\title{
Chronic Eosinophilic Pneumonia
}

National Cancer Institute

\section{Source}

National Cancer Institute. Chronic Eosinophilic Pneumonia. NCI Thesaurus. Code C34471.

Chronic inflammatory disorder of the lungs characterized by the presence of eosinophils in the interalveolar septa and alveolar spaces and peripheral blood eosinophilia. Chest xrays reveal peripheral infiltrates. Approximately half of the patients have history of asthma or atopic disease. Signs and symptoms include fever, dyspnea, cough, and weight loss. Following treatment with corticosteroids, the eosinophilic infiltrates in the lungs disappear, resulting in dramatic clinical improvement. 